\title{
Discussion on the Restriction Factors of Economic Mathematics and the Resolution Strategies
}

\author{
Qinghua Li \\ Business School, Xi'an International University, Xi'an Shaanxi, 710077, China
}

Keywords: Economic mathematics, Restriction factors, Solving strategies

\begin{abstract}
Economic mathematics is the compulsory specialized courses of the logistics major, business administration major and accounting major, mathematics basis of these students in their former study is poor, they are lacking of right thinking for mathematics leaning, and have a distance with common university students on their math theory ability and problem solving ability, with the rapid development of socialist market economy and our country's science and technology, economic mathematics shows its huge social application value, during our country's education reform process, we must realize that economic mathematics is faces huge difficulty, this paper mainly analyzed the restriction factors of economic mathematics and put forward relevant solving strategies.
\end{abstract}

\section{Introduction}

With the rapid development of socialist market economy and our country's science and technology, economic mathematics shows its huge social application value, economic mathematics is a professional compulsory course in the higher vocational education, it is benefit to improve students' creative thinking ability, logic thinking ability and problem analyzing and solving ability, while in the education reform process, we must realize that economic mathematics always faces difficulty in its teaching, students' understanding ability on economic mathematics is low, and they are lack of interests, how to improve the teaching efficiency of economic mathematics is a concerned problem for current educators.

\section{Analysis on the restriction factor of economic mathematics learning}

\section{Students' mathematics basis is weak.}

Economic mathematics is the compulsory specialized courses of the logistics major, business administration major and accounting major, mathematics basis of these students in their former study is poor, they are lacking of right thinking for mathematics leaning, and have a distance with common university students, on one hand, their mathematics performance in the high school is poor, in order to improve enrollment rate, many high school teachers ignored this part of students, which led them gradually lost interest in learning mathematics, they did not timely consolidate and practice on their mathematics, which led to the obvious fault in the mathematics foundation in the high school.

The speciality and logicality of economic mathematics restrict students' learning effects.

Economic mathematics is the main higher mathematics course for economic and management majors, it has strong speciality and logicality, its teaching content includes: linear algebra, mathematical statistics, probability theory, dual function calculus, one function calculus, its is with strong speciality, and has a high requirement on students' logical thinking ability, and with various contents and complicated knowledge system, even for a common college student, it is difficult to understand and use, for the higher vocational students who have weak economic mathematics foundation is more difficult, our economic mathematics materials for high vocational students are with complicated contents, students' class hour is obviously not enough, teachers need at least 23 class hours to finish teaching task of one book, but for the higher vocational education, school arranged much of time on the training for skill and professional knowledge, class hours for economic mathematics is obviously not enough, which leads to the contradiction in the higher vocational education, if teachers can not carefully explain example, theorem and concept in the lesson, students 
cannot under the basic contents in the material, based on this contradiction, teachers always pay attention to the contents related to the examination, the explanation for economic mathematics is very single-facet, naturally students are hard to grasp the knowledge of economic mathematics.

The teaching technology and means for economic mathematics teaching in the higher vocational education is lagging behind.

With the rapid development of science and technology, all kind of advanced teaching technological equipment and means are used in our practical teaching, but for the higher vocational education, schools did not input much money in its teaching equipment and technology, which leads that they always use the traditional teaching means, and are separated from the development tendency, they did not consider students' development situation, thus their education reform is always lagging behind, for the economic mathematics, its contents are complicated, it is inevitable to waste much time on lesson preparation and black-board writing, while after using electronic teaching and multi-media teaching, teachers can save much more time to consolidate students' knowledge, at the same time, by using the computer-assisted introduction can greatly stimulate students' learning interest, make students participate in the study of economic mathematics with enthusiasm, thus then can effectively understand and grasp relevant knowledge and improve their learning efficiency.

\section{Solving strategies for the restriction factors of economic mathematics study}

\section{Reform the traditional teaching materials of economic mathematics, strengthen its functional principle.}

The content of teaching material of economic mathematics is very difficult and complicated, it did not consider students' real situation and acceptance ability,though through many editions, made some changes on the difficult contents, but the change is small as a whole, for higher vocational students, it is still too difficult, and the arrangement of its contents is with bigger reasonable places, introduced too much mathematics knowledge but little economic application knowledge, which seriously deviated from the principle of "economy for use, mathematics as body" with the rapid development of socialist market economy, practical talents are gradually accepted by the society, while the students only focus on theoretical knowledge cannot adapt to the development trend of the society,in recent years, our country's economic system is gradually perfecting, the level of socialist modernization is gradually improved, the higher vocational education must start from the real situation,teaching of economic mathematics cannot just depends on the teaching of pure theoretical knowledge, in the reform process of teaching material of economic mathematics, but also insist to integrate mathematics knowledge with economic principles, insist the combine teaching of economy and mathematics, change the teaching material to adapt to the form that suitable for students' development.

\section{Change teachers' teaching means and methods.}

Practice has proved that traditional teaching means and methods already cannot meet the requirement of social development,with the constant process of science and technology and the rapid development of computer technology, advanced teaching technology and means are gradually popularized and applied in different universities,the era that teach with one chalk and blackboard has already past,teachers of economic mathematics should also set the time spirit of advancing with times,tightly follow up the space of the time,accelerate to improve teaching means for economic mathematics, in the teaching process, combine the blackboard writing with multi-media teaching technology, to build good learning atmosphere for students, it is important to noted that at the same time with improving teaching means, teachers cannot just depend on multi-media technology to stimulate students' interests,we also should to positively make use of the advantage of blackboard writing,strengthen the combination of these two teaching means, fully motivate students' enthusiasm for learning economic mathematics, besides, teachers also can use internet teaching,establish network contacts with students after class,answer for students' questions timely, also can use mathematics knowledge competition to stimulate students' learning enthusiasm to improve teaching quality.For teaching methods,teachers can use examples to explain learning method and concept for 
mathematics,make students unconsciously deepen their understanding on mathematics knowledge, also can use problem-driving method and the form of class discussion to improve students' grasp of economic mathematics knowledge,thus to improve teaching efficiency.Teachers of economic mathematics should fully realize the positive meaning of teaching technical means on students' learning, change the traditional views and values, establish the time spirit, deep education system reform, all use of teaching means should consider students' learning efficiency, put students on the position of the main body of education and teaching, pay attention to students' individual development, give full play to students' creative thinking, help students grasp the correct method for learning economic mathematics, cultivate good learning habit, comprehensively improve students quality.

\section{Strengthen students' confidence.}

Economic mathematics is a professional course for economic and management students,most of these students were literal art students in their high school,with bad mathematics foundation,have distance with common university students on their logical thinking ability,facing the difficult economic mathematics,they are fear of it at the very beginning, besides doubt on their learning ability from the society,make them hard to establish confidence when contact this subject with strong speciality and theoretical property,they denied themselves,for these phenomenon, teacher should make ideological education work for students,firstly, they need to help students establish confidence for learning economic mathematics,help students to overcome their fears,combine real examples in their teaching,make students realize it is very interesting to study economic mathematics,and connect economic mathematics with our daily life, realize its great value in our daily life,strengthen students' attention on learning economic mathematics,besides, teachers should also encourage students during their teaching process,make positive evaluations on students' good performance,make students feel the pleasure of success, thus to improve their confidence in economic mathematics.

\section{Conclusion}

The reason why call this course as economic mathematics,expressed this course has close relationships between economy and mathematics,we should also pay attention to this relation during the teaching process, cannot just teach mathematics knowledge,also cannot just pay attention to the teaching of economic knowledge,for the above mentioned restriction factors, teachers should pay attention to these factors during the teaching process,positively improve their teaching means and methods,carry out teaching on the basis of students' learning situation and acceptance ability,in the teaching process,use modern teaching equipment,establish time spirit,stimulate students' learning interest and comprehensively improve the students' learning quality of economic mathematics.

\section{References}

[1] Lin Hongcheng. Discussion on the Learning Restriction Factors of Economic Mathematics and its Countermeasures. China Market. 2009(22)

[2] Tao Peigen. Self-learning Method of Economic Mathematics. Distance Education Journal.2007

[3] 2009(03) Zhang Yi, Cai Sheng. Difference of Teaching Methods for Economic Mathematics in Higher Education in Different Levels. Journal Of Shenyang University.2009(03)

[4] Wang Wei. Discussion on the Transition from “Teaching” to "Guidance Learning” of Economic Mathematics. Theoretical Observation. 2007(04)

[5] Liu Yuhong. Application of Economic Mathematics on Economic Management. Shanxi Statistics. 2007(05)

[6] Zhao Libin. Discussion on the 21th Century Economic Mathematics and Its Course Content Reform .Journal of Harbin University of Commerce (JCR Social Science Edition). 2007(01) 
[7] Wei Liren. In Memory of Professor Liu Wen--the Editorial Member of Economic Mathematics. Economic Mathematics. 2008(03)

[8] Li Linyu, Hu Xiuzhen. Practice and Cognition on the Teaching Material Construction of Economic Mathematics. Journal of Tianjin Radio and Television University. 2007(03)

[9] Xia Li. Application of Economic Mathematics in the Prediction of Population Education Degree. Journal of Chongqing Industry and Commerce University (JCR Science Edition). 2007(01) 